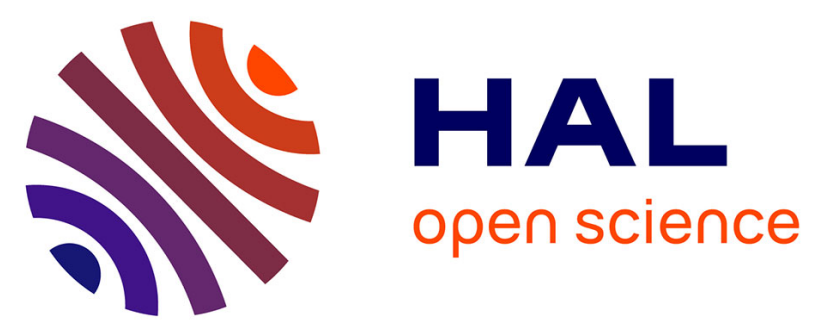

\title{
Molecular tectonics: anion control of dimensionality and connectivity in meta-pyridyl appended tetramercaptotetrathiacalix[4]arene based silver coordination networks
}

Alexander Ovsyannikov, Sylvie Ferlay, Svetlana Solovieva, Igor Antipin, A. Konovalov, Nathalie Kyritsakas, Mir Wais Hosseini

\section{To cite this version:}

Alexander Ovsyannikov, Sylvie Ferlay, Svetlana Solovieva, Igor Antipin, A. Konovalov, et al.. Molecular tectonics: anion control of dimensionality and connectivity in meta-pyridyl appended tetramercaptotetrathiacalix[4]arene based silver coordination networks. Dalton Transactions, 2014, 43 (1), pp.158-165. 10.1039/C3DT52654B . hal-02301079

\author{
HAL Id: hal-02301079 \\ https://hal.science/hal-02301079
}

Submitted on 25 Nov 2020

HAL is a multi-disciplinary open access archive for the deposit and dissemination of scientific research documents, whether they are published or not. The documents may come from teaching and research institutions in France or abroad, or from public or private research centers.
L'archive ouverte pluridisciplinaire HAL, est destinée au dépôt et à la diffusion de documents scientifiques de niveau recherche, publiés ou non, émanant des établissements d'enseignement et de recherche français ou étrangers, des laboratoires publics ou privés. 


\title{
Molecular tectonics: anion control of dimensionality and connectivity in meta-pyridyl appended tetramercaptotetrathiacalix[4]arene based silver coordination networks
}

\author{
A. Ovsyannikov, ${ }^{\text {a,b }}$ S. Ferlay, ${ }^{{ }^{a}}$ S. E. Solovieva, ${ }^{b}$ I. S. Antipin, ${ }^{\text {b,c }}$ A. I. Konovalov ${ }^{b}$, N. Kyritsakas, ${ }^{a}$ M. W. \\ ${ }_{5}$ Hosseini $^{* a}$
}

Received (in XXX, XXX) Xth XXXXXXXXX 20XX, Accepted Xth XXXXXXXXX 20XX

DOI: 10.1039/b000000x

The combination of the same organic tecton $\mathbf{1}$, a meta-pyridyl appended

tetramercaptotetrathiacalix[4]arene in 1,3-alternate conformation offering four pyridyl units and eight

10 thioether groups, with $\mathrm{AgX}\left(\mathrm{X}=\mathrm{BF}_{4}{ }^{-}, \mathrm{NO}_{3}{ }^{-}\right.$and $\left.\mathrm{SbF}_{6}{ }^{-}\right)$silver salts leads, under identical conditions

(concentration, temperature and solvent system), to the formation of different silver coordination

networks. Both the connectivity and the dimensionality of the three silver coordination networks depend on the nature of the anion used as counter ion. Whereas for the weakly coordinating $\mathrm{BF}_{4}^{-}$anion, the latter does not participate in the formation of the non-tubular $1 \mathrm{D}$ coordination network, the coordinating $\mathrm{NO}_{3}{ }^{-}$

15 anion is bound to the metal cation and leads to the formation of a tubular 1D silver coordination network.

For both cases, the eight $\mathrm{S}$ atoms of the tecton $\mathbf{1}$ do not take part in the binding of the cation. In marked contrast, when $\mathrm{SbF}_{6}{ }^{-}$anion is used as counter ion, the organic tecton $\mathbf{1}$ behaves as a tetrakismonodentate through its four meta-pyridyl moieties and as a bischelating unit of the SCCS type leading thus to the formation of a porous $3 \mathrm{D}$ diamondoid-type network.

\section{${ }_{20}$ Introduction}

The formation of Coordination Polymers $(\mathrm{CPs})^{1}$ or coordination networks, ${ }^{2}$ extended periodic architectures generated upon mutual bridging between organic tectons and metal centres, has been the subject of considerable efforts over the past two 25 decades. ${ }^{3}$ The interest in this class of solid state molecular materials arises from either their applications in catalysis, separation and storage or from their physical properties such as electronic, optic, magnetism, conduction, etc. The design of this type or architecture still remains challenging owing to several 30 parameters governing their formation by self-assembly processes. ${ }^{4}$ For some time now, we are exploring an approach called molecular tectonics, ${ }^{5,6,7,8}$ for which, molecular networks such as coordination polymers are considered as extended periodic structures resulting from combinations of 35 complementary organic and metallic tectons capable of interacting together. This approach seems rather efficient for the design of systems composed of two components such as an anionic organic tectons and a metal cations with charge compensation between the two partners or a neutral organic 40 tecton and a neutral metal complex. ${ }^{9}$ However, for combinations based on neutral organic tectons and metal cations, since for charge neutrality reason the presence of anions is required, the system is composed of three components. ${ }^{10}$ Although, with our present state of knowledge one may design specific interactions

45 between the organic tecton and the metal centre, the role played by anions, necessarily present in the crystal, remains unclear in majority of cases. Thus, a better understanding of this type of three component systems requires systematic investigations. ${ }^{11}$

In this contribution, we have considered combinations of the so same neutral organic tecton, a calixarene based tecton 1 (Scheme 1) in an imposed 1,3-alternate conformation bearing four monodentate coordinating sites, the same metal cation $\left(\mathrm{Ag}^{+}\right)$and three different monoanions $\left(\mathrm{NO}_{3}^{-}, \mathrm{BF}_{4}^{-}\right.$and $\left.\mathrm{SbF}_{6}^{-}\right)$with different binding propensity. The aim of the study was to investigate the 5 role played by the anion on the connectivity and thus dimensionality of the silver coordination networks, formed by bridging of consecutive organic tectons by $\mathrm{Ag}^{+}$cations.

\section{Choice of tecton, metal cation and anions}

For the design of organic tectons forming coordination 60 networks in the presence of metal cations, macrocyclic backbones such as calix[4]arene ${ }^{\prime 2}$ and [1111]metacyclophane in 1,3-alternate conformation are of particular interest. Indeed, for such a conformation, four coordinating sites may be introduced in a divergent fashion bellow and above the main plane of the cyclic ${ }_{65}$ backbone. The localisation of the appended coordinating sites at the apices of a tetrahedron leads to a building unit displaying a S4 axis of symmetry.

Whereas the cyclophane backbone adopts a stable and rather rigid 1,3-alternate conformation for steric reasons, the latter 70 conformation may be imposed by proper functionalization of the calix moiety at the lower rim by bulky substituents blocking the conformation flexibility. 
The calix[4]arene backbone locked in 1,3-alternate conformation has been also used for the formation of a helical $\mathrm{H}$-bonded network. $^{14}$

Among the calix family, thiacalix[4]arene (TCA) derivatives for 5 which all four $\mathrm{CH}_{2}$ groups connecting the phenol moieties are replaced by $\mathrm{S}$ atoms, ${ }^{15}$ in addition to the above mentioned features, offer four additional coordinating sites of the thioether type (Ph-S-Ph). Only few examples of coordination networks based on TCA derivatives have been reported to date. TCA 10 derivatives in 1,3-alternate conformation bearing mainly at the lower rim peripheral coordinating sites such as nitrile, ${ }^{16}$ carboxylate $^{17}$, benzonitrile groups ${ }^{18}$, propoxy groups ${ }^{19}$ or pyridy ${ }^{20}$ have been used to generate a variety of 1-, 2- and 3-D coordination networks in the presence of $\mathrm{Ag}^{+}$or $\mathrm{Hg}^{2+}$ cations.

15 Within the thiacalix[4]arene class of compounds, tetramercaptotetrathiacalix[4]arene (TMTCA), an analogue of TCA for which all four $\mathrm{OH}$ moieties are replaced by $\mathrm{SH}$ groups, ${ }^{21}$ is another interesting backbone for the design of organic tectons. Indeed, for the derivative in 1,3-alternate conformation, all four ${ }_{20} \mathrm{SH}$ groups may be functionalized by coordinating sites leading thus to a tecton offering 12 potential sites in a rather confined space which may take part in the binding of metal centres. Few examples of functionalization of the lower rim of TMTCA have been described. ${ }^{22,23}$ The metal binding ability of TMTCA has 25 been investigated and few discrete complexes have been reported for $\mathrm{Ir}(\mathrm{II})$ and $\mathrm{Rh}(\mathrm{II})^{24}, \mathrm{Mo}(\mathrm{II}), \mathrm{Ni}(\mathrm{II})$ and $\mathrm{W}(\mathrm{II})^{25}$ and $\mathrm{Hg}(\mathrm{II}) .{ }^{26} \mathrm{~A}$ specific $\mathrm{Hg}$ (II) extracting agent based on an analogue of TMTCA bearing only two $\mathrm{SH}$ groups has been also reported. ${ }^{27}$ Recently, examples of coordination networks based on combinations of

30 TMTCA appended with four pyridyl groups and $\mathrm{Hg}$ (II) cation have been reported. ${ }^{28}$
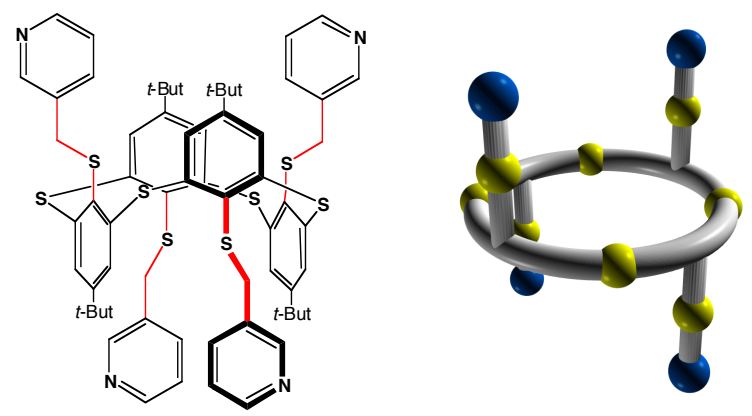

Figure 1: Tecton 1 base on the tetramercaptotetrathiacalix[4]arene (TMTCA) backbone equipped with four meta-pyridyl coordinating sites

(left) and its schematic representation showing its 1,3-alternate conformation (right).

For the present study, the tecton 1, based on the tetramercaptotetrathiacalix[4]arene backbone equipped with four pyridyl coordinating sites, was chosen (Fig. 1). All four pyridyl 40 units were connected to the backbone using the meta position on the aromatic cycle. The latter was attached to the calix platform using methylene spacers. Finally, junctions between the two parts were ensured by thioether groups. It is worth noting that, although the calix backbone is blocked in its 1,3-alternate ${ }_{45}$ conformation, as previously established by X-ray diffraction, ${ }^{23}$ the tecton 1, owing to the presence of $\mathrm{CH}_{2}$ spacers and $\mathrm{C}_{\mathrm{Ph}}-\mathrm{S}-\mathrm{CH}_{2}$ single bonds, may adopt six different extreme rotamers differing by the relative orientation of the $\mathrm{N}$ atoms of the pyridyl moieties, i.e. towards the interior ( $i$ for in) or exterior ( $o$ for out) of the 50 macrocyclic unit (Fig. 2). Furthermore, owing to the presence of eight thioether groups and for pyridyl units in a rather confined space, the tecton 1 may behave as a N4 S8 coordinating tecton. These features, bringing considerable flexibility and binding possibilities, could lead to the control of the connectivity and thus 55 the dimensionality of coordination networks by the nature of the anion when the tecton $\mathbf{1}$ is combined with the same metal cation and different anions.

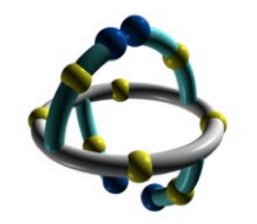

$(\mathrm{i}, \mathrm{i}, \mathrm{i}, \mathrm{i})$

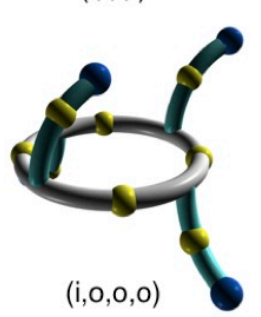

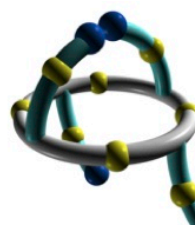

$(\mathrm{i}, \mathrm{i}, \mathrm{i}, \mathrm{o})$

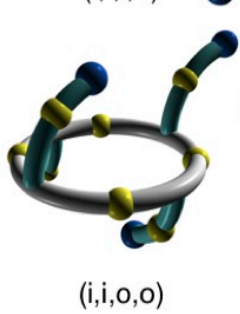

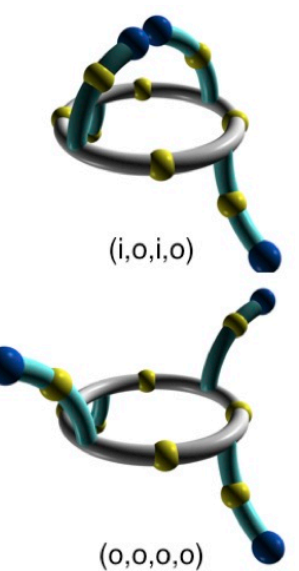

$(0,0,0,0)$
60 Figure 2: Schematic representations of different extreme rotamers which may be adopted by the tecton $\mathbf{1}$ in 1,3-alternate conformation ( $\mathrm{S}$ and $\mathrm{N}$ atoms are presented as yellow and blue spheres respectively). These species result from the rotational freedom brought by the $\mathrm{CH}_{2}$ groups linking the pyridyl groups to the backbone and by the $\mathrm{Cph}_{\mathrm{Ph}}-\mathrm{SCH}_{2}$ single 65 bonds junctions. The rotamers differ by the relative orientation of the $\mathrm{N}$ atoms of the pyridyl moieties ( $i$ and $o$ for in and out respectively).

As the metal centre, $\mathrm{Ag}^{+}$cation was chosen because of its rather loose coordination requirements both in terms of coordination number and geometry. Finally, as anion, $\mathrm{NO}_{3}, \mathrm{BF}_{4}$, 70 and $\mathrm{SbF}_{6}$ have been considered. Although these anions bear a single negative charge, they display different charge density, with nitrate offering the highest and hexafluoroantimonate the lowest. These three anions also differ by their binding propensity with $\mathrm{NO}_{3}$ anion being the most coordinating one. Finally, they also 75 display differences in their size and geometry ranging from trigonal for $\mathrm{NO}_{3}$ to tetrahedral for $\mathrm{BF}_{4}$ and octahedral for $\mathrm{SbF}_{6}$.

Crystallisation processes in general and formation of molecular networks in the crystalline phase in particular are rather whimsical and often depend on several experimental parameters 80 such as concentrations of components, temperature, solvent-nonsolvent system, speed of diffusion and time of evaporation. Not only these parameters control the formation of crystalline materials but they might also lead to different connectivity patterns, dimensionality and polymorphs. In order to control all 85 these extrinsic parameters, the same protocol was used for all combinations of 1 with $\mathrm{AgX}\left(\mathrm{X}=\mathrm{NO}_{3}, \mathrm{BF}_{4}, \mathrm{SbF}_{6}\right)$, leading to the following extended architecture: $\left\{\mathbf{1}-\mathrm{AgNO}_{3}\right\}_{\mathrm{n}},\left\{\mathbf{1}-\mathrm{AgBF}_{4}\right\}_{\mathrm{n}}$ and $\{\mathbf{1}-$ $\left.\mathrm{AgSbF}_{6}\right\}_{n}$. The crystallisation was performed by slow liquid/liquid diffusion at room temperature using identical crystallisation tubes 90 (4 mm diameter, $15 \mathrm{~cm}$ height). The same volume $(1 \mathrm{~mL})$ of solvent $\left(\mathrm{CHCl}_{3}\right)$ was used to solubilise the same amount $(5 \mathrm{mg}$, $4.35 \mu \mathrm{mol}$ ) of tecton $\mathbf{1}$. The solution containing the organic tecton was layered with the same volume $(1 \mathrm{~mL})$ of $\mathrm{CHCl}_{3} /$ iso- $\mathrm{PrOH}$ 
(1/1) mixture used as a buffer. Finally, the silver salt $(1.7 \mathrm{mg}$, $8.73 \mu \mathrm{mol}$ of $\mathrm{AgBF}_{4}, 1.5 \mathrm{mg}, 8.73 \mu \mathrm{mol}$ of $\mathrm{AgNO}_{3}, 3 \mathrm{mg}, 8.72$ $\mu \mathrm{mol}$ of $\left.\mathrm{AgSbF}_{6}\right)$ dissolved in the same volume $(1 \mathrm{~mL})$ of $\mathrm{MeOH}$ was added (see Experimental section). The crystallisation process 5 was stopped after two weeks and single crystals thus obtained studied by X-ray diffraction on single crystals (see experimental section and crystallographic table 1). The purity of all three phases was confirmed elemental analysis for all three crystalline materials and by $\mathrm{X}$-ray diffraction on microcrystalline powders

10 for $\mathbf{1}-\mathrm{AgBF}_{4}$ and $\mathbf{1}-\mathrm{AgSbF}_{6}$. Unfortunately, for $\mathrm{AgNO}_{3}$, we were not able to prepare enough microcrystalline powder.

\section{Experimental part}

Microanalyses were performed by the Service de Microanalyses de la Fédération de Recherche Chimie, Université de Strasbourg, 15 Strasbourg, France.

\section{X-ray diffraction on Single-Crystal}

Data were collected at 173(2) K on a Bruker APEX8 CCD Diffractometer equipped with an Oxford Cryosystem liquid $\mathrm{N}_{2}$ device, using graphite-monochromated Mo-K $\alpha(\lambda=0.71073 \AA)$ 20 radiation. For both structures, diffraction data were corrected for absorption. Structures were solved using SHELXS-97 and refined by full matrix least-squares on $F^{2}$ using SHELXL-97. The hydrogen atoms were introduced at calculated positions and not refined (riding model). ${ }^{29}$ They can be obtained free of charge 25 from the Cambridge Crystallographic Data Centre via www.ccdc.cam.ac.uk/datarequest/cif. CCDC: 957507-957509.

\section{X-ray Diffraction on microcrystalline powder}

Powder X-ray diffraction (PXRD) diagrams were collected for 1$\mathrm{AgBF}_{4}$ and $1-\mathrm{AgSbF}_{6}$ on a Bruker D8 diffractometer using 30 monochromatic $\mathrm{Cu}-\mathrm{K} \alpha$ radiation with a scanning range between 3.8 and $40^{\circ}$ using a scan step size of $2 \% \mathrm{mn}$.

As already demonstrated and currently admitted, for all compounds, discrepancies in intensity between the observed and simulated patterns are due to preferential orientations of the 35 microcrystalline powders.

Synthesis

All reagents were purchased from commercial sources and used without further purification. The tecton 1 was prepared according to reported procedues. ${ }^{23}$

\section{${ }_{40}$ Crystallisation conditions}

1- $\mathrm{AgBF}_{4}$ : In a crystallization tube (diameter $4 \mathrm{~mm}$, height $15 \mathrm{~cm}$ ), a solution of $1\left(5 \mathrm{mg}, 4.35 \times 10^{-3} \mathrm{mmol}\right)$ in $\mathrm{CHCl}_{3}(1 \mathrm{~mL})$ was layered with a $\mathrm{CHCl}_{3} /$ iso- $\mathrm{PrOH}(1 / 1)$ mixture $(1 \mathrm{~mL})$. A solution of $\mathrm{AgBF}_{4}\left(1.7 \mathrm{mg}, 8.73 \times 10^{-3} \mathrm{mmol}\right)$ in $\mathrm{MeOH}(1 \mathrm{~mL})$ was 45 carefully added. Slow diffusion at room temperature and in the dark followed by slow evaporation produced after 2 weeks colourless crystals (4.2 mg, $72 \%$ yield) suitable for X-ray diffraction studies. Anal. Calcd. for $\mathrm{C}_{64} \mathrm{H}_{68} \mathrm{~N}_{4} \mathrm{~S}_{8} \mathrm{AgBF}_{4}: \mathrm{C}$, 57.17\%; H, 5.10\%; N, 4.17\%; Found: C, 57.25\%; H, $5.12 \%$; N, ${ }_{50} 4.16 \%$. IR, $v=2961,1465,1435,1358,1246,1026,890 \mathrm{~cm}^{-1}$.

1- $\mathrm{AgNO}_{3}$ : In a crystallization tube (diameter $4 \mathrm{~mm}$, height 15 $\mathrm{cm})$, a solution of $1\left(5 \mathrm{mg}, 4.35 \times 10^{-3} \mathrm{mmol}\right)$ in $\mathrm{CHCl}_{3}(1 \mathrm{~mL})$ was layered with a $\mathrm{CHCl}_{3} /$ iso- $\mathrm{PrOH}(1 / 1)$ mixture $(1 \mathrm{~mL})$. A solution of $\mathrm{AgNO}_{3}\left(1.5 \mathrm{mg}, 8.73 \times 10^{-3} \mathrm{mmol}\right)$ in $\mathrm{MeOH}(1 \mathrm{~mL})$ was
55 carefully added. Slow diffusion at room temperature and in the dark followed by slow evaporation produced after two weeks colourless crystals (5 mg, $68 \%$ yield) suitable for X-ray diffraction studies. Anal. Calcd. for $\mathrm{C}_{32} \mathrm{H}_{34} \mathrm{~N}_{2} \mathrm{~S}_{4} \mathrm{AgNO}_{3}$ : C, $51.61 \%$; H, 4.60\%; N, 5.64\%; Found: C, $51.45 \%$; H, $4.62 \%$; N, $605.61 \%$. IR, $v=2964,1457,1401,1347,1232,1028,851 \mathrm{~cm}^{-1}$. 1- $\mathrm{AgSbF}_{6}$ : In a crystallization tube (diameter $4 \mathrm{~mm}$, height 15 $\mathrm{cm})$, a solution of compound $\mathbf{8}\left(5 \mathrm{mg}, 4.36 \times 10^{-3} \mathrm{mmol}\right)$ in $\mathrm{CHCl}_{3}$ $(1 \mathrm{~mL})$ was layered a with $\mathrm{CHCl}_{3} /$ iso-PrOH $(1 / 1)$ mixture $(1 \mathrm{~mL})$. A solution of $\mathrm{AgSbF}_{6}\left(3 \mathrm{mg}, 8.72 \times 10^{-3} \mathrm{mmol}\right)$ in $\mathrm{MeOH}(1 \mathrm{~mL})$ ${ }_{65}$ was carefully added. Slow diffusion at room temperature and in the dark followed by slow evaporation produced after 2 weeks colourless crystals (5 mg, $62 \%$ yield) suitable for X-ray diffraction studies. Anal. Calcd. for $\mathrm{C}_{32} \mathrm{H}_{34} \mathrm{~N}_{2} \mathrm{~S}_{4} \mathrm{AgSbF}_{6}$ : C, 41.84\%; H, 3.73\%; N, 3.05\%; Found: C, 41.95\%; H, 3.75\%; N, $703.04 \%$. IR, $v=2963,1486,1459,1365,1230,1031,823 \mathrm{~cm}^{-1}$.

\section{Results and discussion}

$\mathrm{X}$-ray diffraction investigations on single crystals revealed that in all three cases $\left(\mathbf{1}-\mathrm{AgBF}_{4}, \mathbf{1}-\mathrm{AgNO}_{3}\right.$ and $\left.\mathbf{1}-\mathrm{AgSbF}_{6}\right)$, coordination networks are formed in the solid state. These architectures result 75 from bridging of consecutive tectons $\mathbf{1}$ by silver cations. Interestingly, in all three cases, crystals were not solvates but exclusively composed of tecton $1, \mathrm{Ag}^{+}$cation and anion $\left(\mathrm{NO}_{3}\right.$, $\mathrm{BF}_{4}$ or $\mathrm{SbF}_{6}$ ).

In the discussion presented here after, we do not present detailed 80 structural analysis of the organic tecton $\mathbf{1}$. However, it should be mentioned that in all three cases, the tecton 1 remains rather symmetrical with at least a $C_{2}$ axis of symmetry.

\section{$\mathbf{1 - A g B F}_{4}$}

The combination of $\mathbf{1}$ with $\mathrm{AgBF}_{4}$ leads to the formation of ${ }_{85}$ crystals ( $C 2 / c$ space group) composed of cationic $1 \mathrm{D}$ silver coordination networks $\left(\mathrm{AgBF}_{4}\left(\mathrm{C}_{64} \mathrm{H}_{68} \mathrm{~N}_{4} \mathrm{~S}_{8}\right)\right)$ with a $1 / \mathrm{Ag}^{+}$ratio of $1 / 1$ (see table 1$)$. The $1 \mathrm{D}$ architecture is generated through bridging of consecutive tectons 1 by silver cations. Within the 1D network, the neutral tecton $\mathbf{1}$ is present as the highly symmetrical 90 rotamer (i,i,i,i) (Fig. 2) with all four $\mathrm{N}$ atoms of the pyridyl units inwardly oriented (Fig. 3). Consequently, the tecton $\mathbf{1}$ behaves as a bischelating unit and binds two $\mathrm{Ag}^{+}$cations.

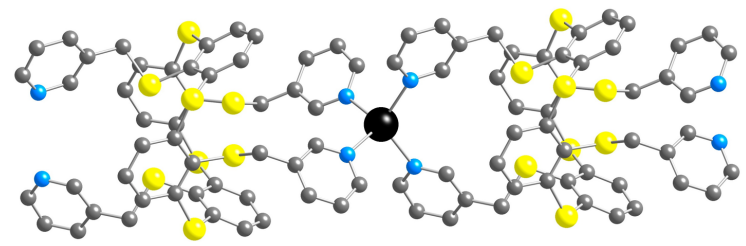

Figure 3: a portion along the $b$ axis of the cationic 1D silver coordination 95 network formed by combination of the organic tectons 1 with $\mathrm{AgBF}_{4}$ salt. $\mathrm{H}$ atoms and $\mathrm{BF}_{4}^{-}$anions are not presented for clarity. For bond angles and distances see text.

The silver cation is tetracoordinated and surrounded by four $\mathrm{N}$ atoms belonging to two consecutive tectons 1 with $\mathrm{Ag}-\mathrm{N}$ 100 distances of 2.294(3) and 2.326(3) A. The metal cation adopts a slightly distorted tetrahedral coordination geometry with NAgN angles in the $102.97(11)-115.89(16)^{\circ}$ range (Fig. 3). The observed connectivity pattern leads to a non-tubular 1D network running along the $b$ axis. This type of architecture with the same 105 connectivity has already been observed for calix[4]arene, ${ }^{30}$ and 
thiacalixarene ${ }^{18}$ based tectons appended with four monodentate coordinating sites. Within the 1-D network, the distance between consecutive $\mathrm{Ag}^{+}$cations is $14.5274(10) \AA$ which corresponds to the $a$ parameter. It is worth noting that none of the eight $\mathrm{S}$ atoms 5 are involved in any type of interaction with the silver cation.

Within the crystal, the 1D networks are packed in a parallel fashion along the $a$ and $c$ axis (Fig. 4). The interstices are occupied by $\mathrm{BF}_{4}^{-}$anions without any specific interaction with the organic tecton $\mathbf{1}$ or $\mathrm{Ag}^{+}$cation. However, a rather short $\mathrm{F} \cdots \mathrm{F}$ 10 distance of $1.798(12) \AA$ ) is observed.

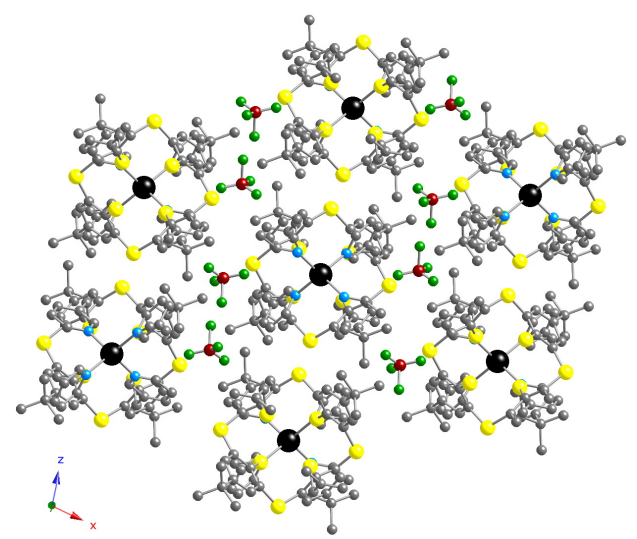

Figure 4: packing of the 1D networks in the $\mathrm{xOz}$ plane showing the localisation of $\mathrm{BF}_{4}^{-}$anions within the empty spaces and the short distance between consecutive anions. $\mathrm{H}$ atoms are omitted for clarity. For bond distances and angles see text.

15 The purity of the $1-\mathrm{AgBF}_{4}$ crystalline phase was established by PXRD (See ESI, Fig. S1) on a microcrystalline powder which revealed a good match between the observed (Fig. S1 top) and simulated patterns from the XRD data on single crystal (Fig. S1 bottom).

\section{1- $\mathrm{AgNO}_{3}$}

The combination of 1 with $\mathrm{AgNO}_{3}$ affords again crystals $(\mathrm{C} 2 / \mathrm{c}$ space group, see table 1) composed of cationic 1D coordination networks $\left(\left(\mathrm{AgNO}_{3}\right)_{2}\left(\mathrm{C}_{64} \mathrm{H}_{68} \mathrm{~N}_{4} \mathrm{~S}_{8}\right)\right)$ with a $\mathbf{1} / \mathrm{Ag}^{+}$ratio of $1 / 2$ (Fig. $255)$. Within the network, the organic tecton 1 although again a rather symmetrical, is present as the $(0,0,0,0)$ rotamer (Fig. 2). The tecton 1 behaves as a tetrakismonodentate unit and binds four $\mathrm{Ag}^{+}$cations. In marked contrast with $1-\mathrm{AgBF}_{4}$, the silver cation is tricoordinated and surrounded by two $\mathrm{N}$ atoms (pyridyl) 30 belonging to two consecutive tectons 1 with a rather short $\mathrm{Ag}-\mathrm{N}$ distance of 2.142(2) $\AA$ and one of the three $\mathrm{O}$ atom of a $\mathrm{NO}_{3}{ }^{-}$ anion with a rather long $\mathrm{Ag}-\mathrm{O}$ distance of $\mathrm{d}_{\mathrm{Ag}-\mathrm{O}}$ long distance of 2.639(2). The metal cation adopts a slightly distorted $\mathrm{T}$ type geometry with $\mathrm{NAgN}$ and $\mathrm{NAgO}$ angles of $170.23(9)^{\circ}$ and ${ }_{35} 86.89(9)^{\circ}$ respectively and thus behaves as a linear connector. The Ag-Ag distance within the 1D network is $8.457 \AA$. Again, as in the case of $1-\mathrm{AgBF}_{4}$, for $\mathbf{1}-\mathrm{AgNO}_{3}$ none of the sulphur atoms interacts with the $\mathrm{Ag}^{+}$cation.

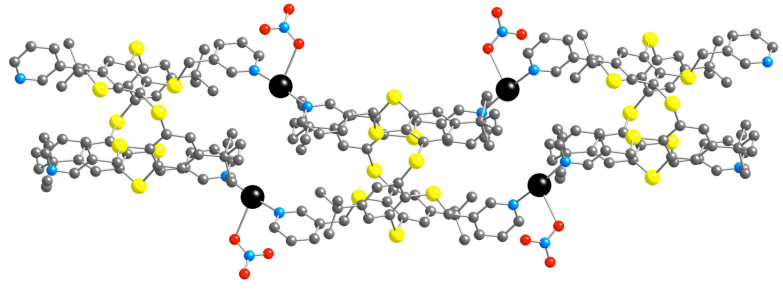

40 Figure 5: a portion along the $c$ axis of the neutral 1D silver coordination network, formed upon combining the organic tectons 1 with $\mathrm{AgNO}_{3}$ salt, showing the binding of the nitrate anion by silver cation bridging consecutive tectons $\mathbf{1}$. H atoms are not presented for clarity. For bond angles and distances see text.

${ }_{45}$ In contrast with what is observe for $1-\mathrm{AgBF}_{4}$ discussed above, the connectivity pattern obtained for $\mathbf{1}-\mathrm{AgNO}_{i}$, leads to a deformed tubular 1D network, running along the $c$ axis. This type of architecture has been previously observed for a [1111]metacyclophane based tecton bearing four pyridyl 50 coordinating moieties. ${ }^{13 \mathrm{~b}, \mathrm{f}, \mathrm{m}}$

In the crystal, the 1D networks are packed in a parallel fashion along the $a$ and $b$ axis (Fig. 6).

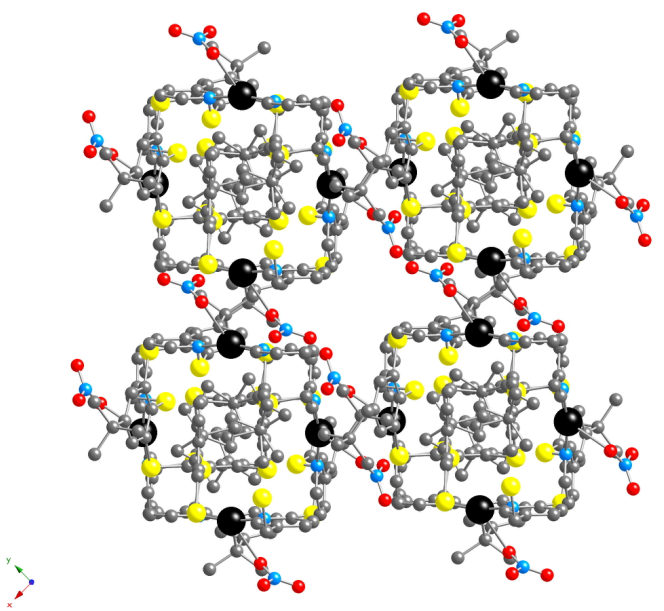

Figure 6: packing of the 1D networks in the xOy plane. $\mathrm{H}$ atoms are omitted for clarity. For bond distances and angles see text.

\section{${ }_{55} \mathbf{1}_{-\mathrm{AgSbF}_{6}}$}

In marked contrast with the $1-\mathrm{AgBF}_{4}$ and $\mathbf{1}-\mathrm{AgNO}_{3}$ discussed above, for $1-\mathrm{AgSbF}_{6}$, a cationic 3D coordination polymer ( $\mathrm{Ag}$ $\left.\mathrm{SbF}_{6}\right)_{2}\left(\mathrm{C}_{64} \mathrm{H}_{68} \mathrm{~N}_{4} \mathrm{~S}_{8}\right)$ ) is obtained (figure 7). The latter crystallises in the trigonal chiral $P_{2} 21$ space group (see table 1). For the ${ }_{60}$ cationic $3 \mathrm{D}$ coordination polymer the $\mathbf{1} / \mathrm{Ag}^{+}$ratio is $1 / 2$. As for $\mathbf{1}$ $\mathrm{AgNO}_{3}$, the $(0,0,0,0)$ rotamer (Fig. 2) of the organic tectons 1 is found in the crystal. The latter displays a $\mathrm{C}_{2}$ axis of symmetry. It is worth noting that the shape adopted by the tecton $\mathbf{1}$ (Fig. 8a) is rather deformed when compared to the one observed for $\mathbf{1}$ in the ${ }_{65}$ absence of metal centre. ${ }^{28}$ Indeed, whereas for the free compound 1, the opposite aryl units are almost parallel to each other (dihedral angles are $1.0^{\circ}$ and $3.5^{\circ}$ ), here, the pendant pyridyl moieties are significantly bent by almost about $90^{\circ}$ with respect to the calixarene backbone main axis. Due to the conformation 70 adopted by $\mathbf{1}$, the latter behaves simultaneously as a tetrakismonodentate ligand (four $\mathrm{N}$ atoms belonging to the pyridyl moieties) and as a bischelating unit (four sulphur atoms belonging to the thioether junctions and two of the thiophenol 
type). Overall, the tecton 1 offers a N4S4 set of coordinating sites (Fig. 8b).

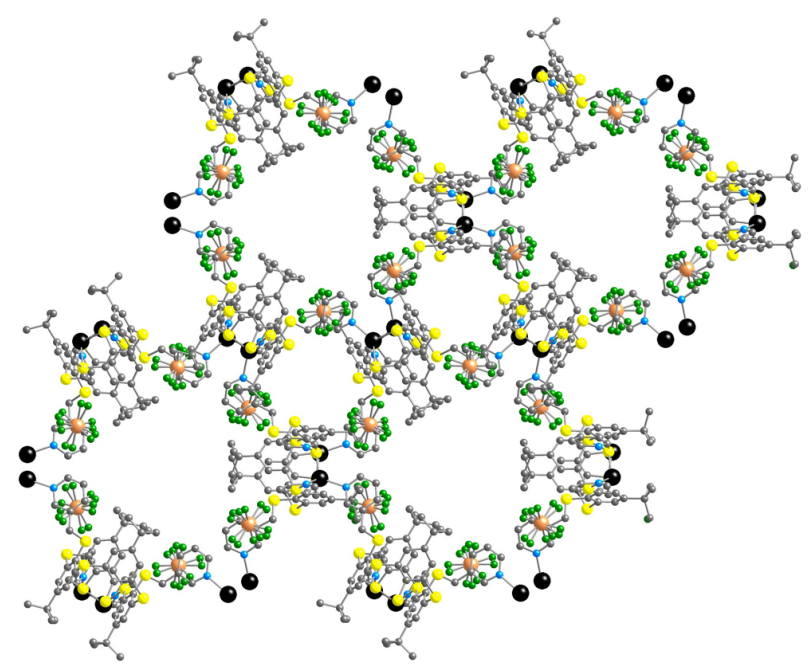

Figure 7: A portion of crystal structure of $1-\mathrm{AgSbF}_{6}$ in the $\mathrm{xOy}$ plane. $\mathrm{H}$ atoms are omitted for clarity. For bond distances and angles see text.

The $\mathrm{Ag}^{+}$cation, is again tetracoordinated as in the case of 1$\mathrm{AgBF}_{4}$, however, its coordination sphere is not composed of four $\mathrm{N}$ atoms but by a $\mathrm{N}_{2} \mathrm{~S}_{2}$ set of coordinating centres. The two $\mathrm{N}$ atoms belong to two consecutive tectons $1\left(\mathrm{~d}_{\mathrm{Ag}-\mathrm{N}}=2.324(15)\right.$ and 2.265(8) $\AA$ ), whereas the two $\mathrm{S}$ atoms belong to the same calix unit ( $\mathrm{d}_{\mathrm{Ag}-\mathrm{S}}$ of 2.617(4) and 2.642(4) $\AA$ ). The geometry adopted by $\mathrm{Ag}^{+}$cation is a highly deformed tetrahedral with $\mathrm{NAgN}$ and SAgS angles of $99.7(16)^{\circ}$ and $78.58(11)^{\circ}$ respectively and the NAgS angle varies between $96.9(5)^{\circ}$ and $133.9(19)^{\circ}$.

The $3 \mathrm{D}$ architecture is rather complex and its description requires a detailed analysis of sub building blocks formed by association of the organic and metallic tectons. Each tecton 1, offering four $\mathrm{N}$ atoms occupying the apices of a deformed tetrahedron (Fig. 9a), binds $6 \mathrm{Ag}^{+}$cations (Fig. 8b). On the other hand, each $\mathrm{Ag}^{+}$cation, also adopting a strongly deformed tetrahedral geometry, is connected to three tectons 1 through two N-Ag bonds with two consecutive tectons 1 and two Ag-S bonds with a SCCS chelating unit of the third tecton 1. Furthermore, $\mathrm{Ag}^{+}$cations are organised in pairs without any Ag-Ag interactions. Within the pair, each cation is connected surrounded by four different tectons 1 (Fig. 8c). Thus, each pair of $\mathrm{Ag}^{+}$cations is surrounded by four tectons 1 leading thus to a deformed tetrahedral nod (Fig. 8d). The overall architecture may be described as a diamondoid-like network resulting from interconnection of tectons $\mathbf{1}$ and the silver dimeric units both behaving as tetrahedral subunits (Fig. 8e).

The connectivity mode leads to a porous structure and as a result of the deformed nature of tetrahedrons composing the diamondoid architecture, two types of pores differing by their seize are generated (Fig. 9e).
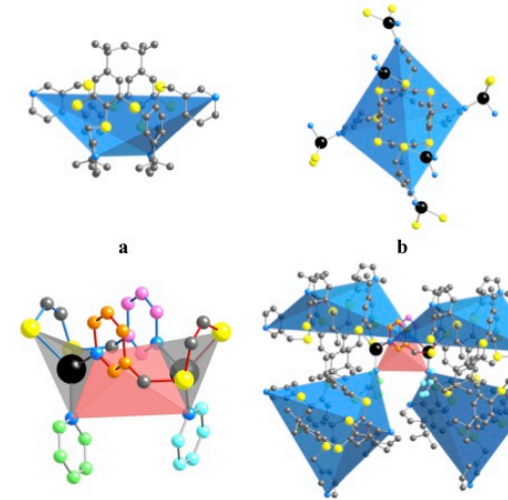

b

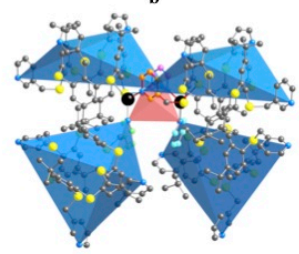

d

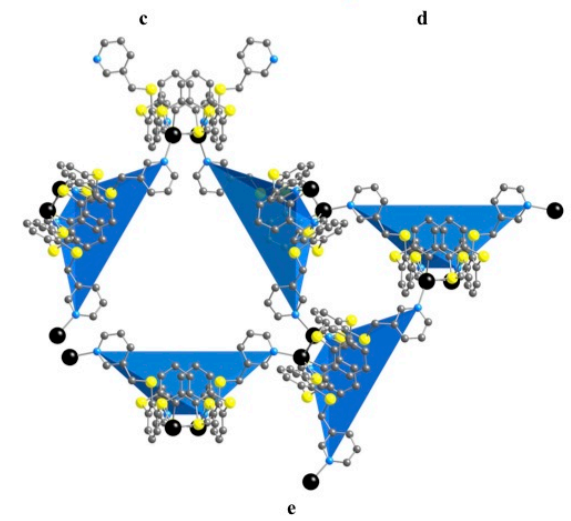

Figure 8: Portions of the 3D diamondoid silver coordination network formed upon combining the tecton 1 with $\mathrm{AgSbF}_{6}$ showing the distorted tetrahedral geometry adopted by 1 (a), the surrounding of the tecton by 6 $\mathrm{Ag}^{+}$cations (b), the formation of a silver dimer (c), the surrounding of the silver dimer by 4 tectons 1 (d) and the connectivity between the two different building subunits leading to two types of cavities (e). For sake of clarity different colours have been used for $\mathrm{C}$ atoms belonging to different calix units in c. $\mathrm{H}$ atoms and $\mathrm{SbF}_{6}{ }^{-}$anions re omitted for clarity. For bond distances and angles see text.

The two types of pores display sections of $c a$. 5.6x5.6 $\AA$ and of ca. $9.8 \times 9.8 \AA$ for the small and the large one respectively.

5 The $\mathrm{SbF}_{6}-$ anions, not participating to the connectivity, are located near the $\mathrm{Ag}^{+}$cations (Fig. 7) with very weak interactions between them $\left(\mathrm{d}_{\mathrm{Ag}-\mathrm{F}}=4.89 \AA\right)$. Furthermore, no specific interactions between the anions and neutral tectons $\mathbf{1}$ are present. As a consequence of the localization of the anions, the channels 10 are not occupied and the crystal is porous.

The purity of the 1-AgSbF 6 phase was established by PXRD on microcrystalline powder which revealed a good match between the observed and simulated patterns from the XRD data (See ESI, Fig. S2).

\section{${ }_{15}$ Conclusions}

The role played by anions on the connectivity, geometry and dimensionality of silver coordination networks was investigated in a systematic fashion by combining the same organic tecton $\mathbf{1}$, based on the tetramercaptotetrathiacalix[4]arene backbone in 1,320 alternate conformation appended with four meta-pyridyl groups as coordinating units, with three silver salts $\mathrm{AgX}\left(\mathrm{X}=\mathrm{BF}_{4}^{-}, \mathrm{NO}_{3}{ }^{-}\right.$ and $\mathrm{SbF}_{6}{ }^{-}$). Three unprecedented architectures for such a tecton were obtained. The crystalline materials were exclusively composed of the organic tecton and the silver salt. The study 
clearly revealed that, under the same experimental conditions, the nature of the anion used to neutralize the charge strongly direct the type of extended architecture formed. Indeed, depending on their geometry, charge density and coordination propensity, 5 anions may or may not bind to the metal cation and thus control the geometry of $\mathrm{Ag}^{+}$as a metallic node. For the weakly coordinating $\mathrm{BF}_{4}^{-}$anion, the latter do not participate to the connectivity of the non-tubular 1D network which is formed by bridging of consecutive (i,i,i,i) rotamer of tectons $\mathbf{1}$, behaving as a 10 bischelating unit, by silver cation adopting a tetrahedral coordination geometry (Fig. 9b). In contrast, for the coordinating $\mathrm{NO}_{3}{ }^{-}$anion, a tubular 1D network is observed. For the latter, consecutive tectons $\mathbf{1}$ are bridged by silver cations adopting a Ttype coordination geometry with the nitrate anion bound to the 15 metal cation (Fig. 11c). In the case of both $\mathrm{BF}_{4}^{-}$and $\mathrm{NO}_{3}{ }^{-}$anion, none of the $8 \mathrm{~S}$ atoms of the tecton $\mathbf{1}$ is involved in the binding of silver cation. In marked contrast with the two architectures mentioned above, for the octahedral weakly coordinating $\mathrm{SbF}_{6}{ }^{-}$ anion, an intriguing porous diamond-like $3 \mathrm{D}$ network is obtained.

${ }_{20}$ In that case, although the anion do not take part in the connectivity of neutral and cationic components, the organic tecton 1 behaves as a tetrakismonodentate and as a bischelating unit. Indeed, in addition to pyridyl coordinating units, four out of the eight $\mathrm{S}$ atoms participate in the binding of $\mathrm{Ag}^{+}$cations as ${ }_{25}$ SCCS chelates (Fig. 9d).

The use of porous crystals of $1-\mathrm{AgPF}_{6}$ based on a 3D network of the diamondoid type for the uptake of gas and small molecules is currently under investigation.

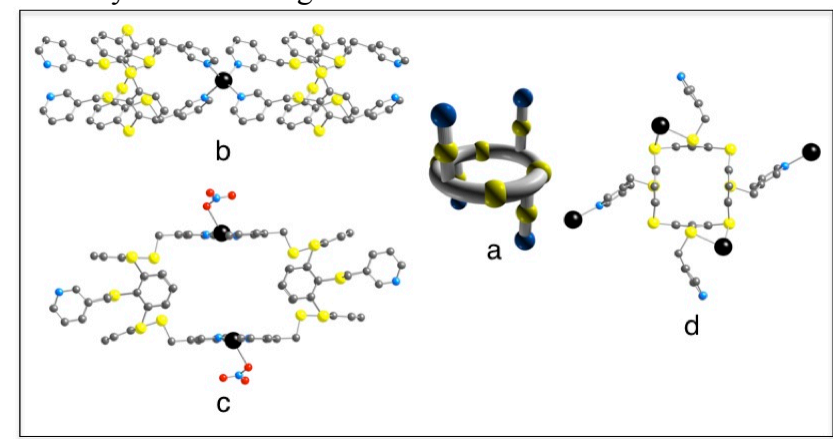

$30 \quad$ Figure 9: Representation of different surroundings observed for the schematically represented organic tecton 1 (a) upon its combination with $\mathrm{AgBF}_{4}(\mathrm{~b}), \mathrm{AgNO}_{s}(\mathrm{c})$ and $\mathrm{AgSbF}_{6}$ (d). Whereas for both $\mathrm{AgBF}_{4}$ and

$\mathrm{AgNO}_{3}$ a $1 \mathrm{D}$ coordination network is obtained, for $\mathrm{AgSbF}_{6}$ a $3 \mathrm{D}$ diamondoid architecture is formed.

\section{${ }_{35}$ Acknowledgments}

We thank the University of Strasbourg, the Institut Universitaire de France (IUF), the International centre for Frontier Research in Chemistry (icFRC), the CNRS and RFBR-CNRS grant $N^{\circ} 12-03-$ 91061, the ARCUS Programme and the Region Alsace (PhD. 40 fellowship to A. O.) for financial support.

\section{Notes and references}

\footnotetext{
${ }^{a}$ Molecular Tectonic Laboratory, UMR UDS-CNRS 7140, icFRC, University of Strasbourg, Institut Le Bel, 4, rue Blaise Pascal, F-67000 Strasbourg, France

${ }_{45}{ }^{b}$ A. E. Arbuzov Institute of Organic and Physical Chemistry, Russian Academy of Science, Arbuzov str. 8, Kazan 420088, Russian Federation
}

${ }^{c}$ Kazan Federal University, Kremlevskaya str. 18, Kazan 420008, Russian Federation

$\dagger$ Electronic Supplementary Information (ESI) available: PXRD traces 50 for $1-\mathrm{AgBF}$ and $1-\mathrm{AgSbF}_{6}$. CCDC 957507-957509. See DOI: $10.1039 / \mathrm{b} 000000 \mathrm{x} /$

[1] (a) B. F. Abrahams, B. F. Hoskins, R. Robson, J. Am. Chem. Soc., 1991, 113, 3606; (b) S. R. Batten, R. Robson, Angew. Chem. Int. Ed., $1998,37,1460$

[2] M. W. Hosseini, CrystEngComm., 2004, 6, 318.

[3] (a) A. J. Blake, N. R. Champness, P. Hubberstey, W.-S. Li, M. A. Withersby, M. Schröder, Coord. Chem. Rev.,1999, 193, 117; (b) B. Moulton, M. J. Zaworotko, Chem. Rev., 2001, 101, 1629; (c) M. Eddaoudi, D. B. Moler, H. Li, B. Chen, T.M. Reineke, M. O'Keeffe, O. M. Yaghi, Acc. Chem. Res., 2001, 34, 319; (d) C. Janiak, Dalton Trans., 2003, 2781; (e) L. Carlucci, G. Ciani, D. M. Proserpio, Coord. Chem. Rev., 2003, 246, 247; (f) S. Kitagawa, R. Kitaura,, S. Noro, Angew. Chem. Int. Ed., 2004, 43, 2334; (g) G. Férey, C. Mellot-Draznieks, C. Serre, F. Millange, Acc. Chem. Res., 2005, 38, 218; (h) D. Bradshaw, J. B. Claridge, E. J. Cussen, T. J. Prior, M. J. Rosseinsky, Acc. Chem. Res., 2005, 38, 273; (i) S. Kitagawa, K. Uemura, Chem. Soc. Rev. 2005, 34, 109 ; (j) D. Maspoch, D. RuizMolina, J. Veciana, Chem. Soc. Rev. 2007, 36, 770; (k) J. R. Long, O. M. Yaghi, Chem. Soc. Rev., 2009, 38, 1213; (1) C. Janiak, J. L. Vieth, New J. Chem., 2010, 34, 2366; (m) Chem. Soc. Rev., 2009, 38, themed issue on metal-organic frameworks; (n) W. L. Leong, J. J. Vittal, Chem. Rev. 2011, 111, 688; (o) Chem. Rev., 2012, 112, MetalOrganic Frameworks special issue.

[4] N. R. Champness, Dalton Trans, 2011, 40, 10311.

[5] (a) M. Simard, D. Su, J. D. Wuest, J. Am. Chem. Soc., 1991, 113, 4696; (b) J. D. Wuest, Chem. Commun., 2005, 5830.

[6] S. Mann, Nature, 1993, 365, 499.

[7] M. W. Hosseini, Acc. Chem. Res., 2005, 38, 313.

[8] M. W. Hosseini, Chem. Commun., 2005, 5825.

[9] A. Jouaiti, M. W. Hosseini, A. De Cian, Chem. Commun., 2000, 1863

[10]A. Jouaiti, V. Jullien, M. W. Hosseini, J.-M. Planeix, A. De Cian, Chem. Commun, 2001, 1114.

[11]D. Pocic, J.-M. Planeix, N. Kyritsakas, A. Jouaiti, M. W. Hosseini, CrystEngComm., 2005, 7, 624.

[12](a) C.D. Gutsche in Calixarenes Revised: Monographs in Supramolecular Chemistry Vol. 6, The Royal Society of Chemistry, Cambridge, 1998; (b) Z. Asfari, V. Böhmer, J. Harrowfield, J. Vicens in Calixarenes 2001, (Eds. Z. Asfari, V. Böhmer, J. Harrowfield, J. Vicens) Kluwer Academic, Dordrecht, 2001.

[13](a) S. Pappalardo, G. Ferguson, J. F. Gallagher, J. Org. Chem., 1992, 57, 7102; (b) C. Klein, E. Graf, M. W. Hosseini, A. De Cian, J. Fischer, Chem. Commun., 2000, 239; (c) X. Delaigue, M. W. Hosseini, Tetrahedron Lett., 1994, 35, 8111; (d) C. Klein, E. Graf, M. W. Hosseini, A. De Cian, New. J. Chem., 2001, 25, 207; (e) C. Klein, E. Graf, M. W. Hosseini, A. De Cian, N. Kyritsakas, Eur. J. Org. Chem., 2002, 802; (f) G. Laugel, E. Graf, M. W. Hosseini, J.-M. Planeix, N. Kyritsakas, New J. Chem., 2006, 30, 1340; (g) C. Klein, E. Graf, M. W. Hosseini, A. De Cian, Tetrahedron Lett., 2000, 41, 9043; (h) C. Klein, E. Graf, M. W. Hosseini, G. Mislin, A. De Cian, Tetrahedron Lett., 2000, 41, 9043; (i) C. Klein, E. Graf, M. W. Hosseini, A. De Cian, N. Kyritsakas-Gruber, Eur. J. Org. Chem., 2003, 395; (j) C. Klein, E. Graf, M. W. Hosseini, N. KyritsakasGruber, Transactions ACA, 2005, 39, 1; (k) C. Klein, E. Graf, M. W. Hosseini, A. De Cian, N. Kyritsakas-Gruber, Eur. J. Inorg. Chem., 2003, 1299; (1) J. Ehrhart, J.-M. Planeix, N. Kyritsakas-Gruber, M. W. Hosseini, Dalton Trans., 2009, 2552; (m) J. Ehrhart, J.-M. Planeix, N. Kyritsakas-Gruber, M. W. Hosseini, Dalton Trans., 2009, 6309; (n) J. Ehrhart, J.-M. Planeix, N. Kyritsakas-Gruber, M. W. Hosseini, Dalton Trans., 2010, 39, 2137.

[14]W. Jaunky, M. W. Hosseini, J.-M. Planeix, A. De Cian, N. Kyritsakas, J. Fischer, Chem. Commun., 1999, 2313.

[15] (a) H. Kumagai, M. Hasegawa, S. Miyanari, Y. Sugawa, Y. Sato, T. Hori, S. Ueda, H. Kamiyama, S. Miyano, Tetrahedron Lett., 1997, 38, 3971; (b) H. Akdas, L. Bringel, E. Graf, M. W. Hosseini, G. 
Mislin, J. Pansanel, A. De Cian, J. Fischer, Tetrahedron Lett., 1998, 39, 2311; (c) M.W. Hosseini in Calixarenes 2001, (Eds. Z. Asfari, V. Böhmer, J. Harrowfield, J. Vicens) Kluwer Academic, Dordrecht, 2001, pp.110.

[16]M. N. Kozlova, S. Ferlay, S. E. Solovieva, I. S. Antipin, A. I. Konovalov, N. Kyritsakas, M. W. Hosseini, Dalton Trans., 2007, 5126.

[17]H. Akdas, E. Graf, M. W. Hosseini, A. De Cian, J. M. Harrowfield, Chem. Commun., 2000, 2219.

[18]M. N. Kozlova, S. Ferlay, N. Kyritsakas, M. W. Hosseini, S. E. Solovieva, I. S. Antipin, A. I. Konovalov, Chem. Commun., 2009, 2514.

[19]J. Sykora, M. Himl, I. Stibor, I. Cisarova, P. Lhotak, Tetrahedron, 2007, 63, 2244.

[20] (a) A. Ovsyannikov, M. N. Lang, S. Ferlay, S. E. Solovieva, I. S. Antipin, A. I. Konovalov, N. Kyritsakas, M. W. Hosseini, Dalton Trans., 2013, 42, 116 (b) A. Ovsyannikov, S. Ferlay, S. E. Solovieva, I. S. Antipin, A. I. Konovalov, N. Kyritsakas, M. W. Hosseini, Dalton Trans., 2013, 42, 9946.

[21] (a) P. Rao, M. W. Hosseini, A. De Cian, J. Fischer, Chem. Commun., 1999, 2169; (b) H. Akdas, E. Graf, M. W. Hosseini, A. de Cian, A.
Bilyk, B. W. Skelton, G. A. Koutsantonis, I. Murray, J. M. Harrowfield, A. H. White, Chem. Commun., 2002, 1042.

[22]H. Akdas, E. Graf, M. W. Hosseini, P. Rao, A. De Cian, J. Supra. Chem., 2002, 2, 21.

[23]H. Akdas, E. Graf, M. W. Hosseini, A. De Cian, N. KyritsakasGruber, C. R. Chimie, 2003, 6, 565 .

[24]K. Hirata, T. Suzuki, A. Noya, I. Takei and M. Hidai, Chem.Commun., 2005, 3718.

[25]D. Buccella, G. Parkin; Chem.Commun., 2009, 289.

[26]H. Akdas, E. Graf, M. W. Hosseini, A. De Cian, A. Bilyk, B. W. Skelton, G. A. Koutsantonis, I. Murray, J. M. Harrowfield, A. H. White, Chem.Commun., 2002, 1042.

[27 P. Rao, O. Enger, E. Graf, M. W. Hosseini, A. De Cian, J. Fischer, Eur. J. Inorg. Chem., 2000, 1503.

[28 A. Ovsyannikov, S. Ferlay, S. E. Solovieva, I. S. Antipin, A. I. Konovalov, N. Kyritsakas, M. W. Hosseini, Inorg. Chem., 2013, 52, 6776.

[29] Sheldrick, G. M.: Program for Crystal Structure Solution; University of Göttingen: Göttingen, Germany, 1997.

[30]G. Mislin, E. Graf, M. W. Hosseini, A. De, Cian, N. Kyritsakas, J. Fischer, Chem. Commun., 1998, 2545. 
Table 1 : Crystallographic Parameters for $1-\mathrm{AgBF}_{4}, \mathbf{1}-\mathrm{AgNO}_{3}$ and $\mathbf{1}-\mathrm{AgSbF}_{6}$ recorded at $173 \mathrm{~K}$.

\begin{tabular}{|c|c|c|c|}
\hline Formula & 1-AgBF $_{4}$ & 1-AgNO $_{3}$ & $1-\mathrm{AgSbF}_{6}$ \\
\hline Meta & $\mathrm{C}_{64} \mathrm{H}_{68} \mathrm{~N}_{4} \mathrm{~S}_{8} \mathrm{AgBF}_{4}$ & $\mathrm{C}_{32} \mathrm{H}_{34} \mathrm{~N}_{2} \mathrm{~S}_{4} \mathrm{AgNO}_{3}$ & $\mathrm{C}_{22} \mathrm{H}_{3} \mathrm{~N}_{2} \mathrm{~S}_{4} \mathrm{AgSbF}_{6}$ \\
\hline Molecular weight & 1344.38 & 896.14 & 918.47 \\
\hline Crystal system & Monoclinic & Monoclinic & Trigonal \\
\hline Space group & $\mathrm{C} 2 / \mathrm{c}$ & $\mathrm{C} 2 / \mathrm{c}$ & $\mathrm{P} 321$ \\
\hline $\mathrm{a}(\AA \AA)$ & $23.1441(10)$ & $17.4196(3)$ & $23.1415(11)$ \\
\hline $\mathrm{b}(\AA)$ & $14.5274(10)$ & $15.7381(3)$ & $23.1415(11)$ \\
\hline$c(\AA)$ & $19.8691(12)$ & $29.2392(6)$ & $15.1463(6)$ \\
\hline$\alpha(\operatorname{deg})$ & 90 & 90 & 90 \\
\hline$\beta(\operatorname{deg})$ & $105.167(4)$ & $97.8830(10)^{\circ}$ & 90 \\
\hline$\gamma(\operatorname{deg})$ & 90 & 90 & 120 \\
\hline $\mathrm{V}\left(\AA^{3}\right)$ & $6447.8(7)$ & $7940.2(3)$ & $7024.6(5)$ \\
\hline $\mathrm{Z}$ & 4 & 8 & 6 \\
\hline Colour & colourless & colourless & colourless \\
\hline Crystal dim (mm3) & $0.09 \times 0.07 \times 0.06$ & $0.07 \times 0.05 \times 0.05$ & $0.09 \times 0.07 \times 0.05$ \\
\hline Dcalc $(\mathrm{gcm}-3)$ & 1.385 & 1.499 & 1.303 \\
\hline $\mathrm{F}(000)$ & 2784 & 3664 & 2736 \\
\hline$\mu(\mathrm{mm}-1)$ & 0.626 & 0.960 & 1.217 \\
\hline Wavelength $(\AA ̊)$ & 0.71073 & 0.71073 & 0.71073 \\
\hline Number of data meas. & 121323 & 45043 & 43790 \\
\hline $\begin{array}{l}\text { Number of data with } \\
\qquad \mathrm{I}>2 \sigma(\mathrm{I})\end{array}$ & $\begin{array}{c}8888[\mathrm{R}(\mathrm{int})= \\
0.0684]\end{array}$ & $\begin{array}{c}11678[\mathrm{R}(\mathrm{int})= \\
0.0387]\end{array}$ & $\begin{array}{c}10045[\mathrm{R}(\mathrm{int})= \\
0.1230]\end{array}$ \\
\hline $\mathrm{R}$ & $\begin{array}{c}\mathrm{R} 1=0.0544, \mathrm{wR} 2= \\
0.1546\end{array}$ & $\begin{array}{c}\mathrm{R} 1=0.0420, \mathrm{wR} 2= \\
0.1048\end{array}$ & $\begin{array}{c}\mathrm{R} 1=0.10947, \mathrm{wR} 2= \\
0.2534\end{array}$ \\
\hline $\mathrm{Rw}$ & $\begin{array}{c}\mathrm{R} 1=0.0899, \mathrm{wR} 2= \\
0.1793\end{array}$ & $\begin{array}{c}\mathrm{R} 1=0.0714, \mathrm{wR} 2= \\
0.1283\end{array}$ & $\begin{array}{c}\mathrm{R} 1=0.1821, \mathrm{wR} 2= \\
0.2995\end{array}$ \\
\hline GOF & 1.013 & 1.035 & 1.186 \\
\hline $\begin{array}{l}\text { Largest peak in final } \\
\text { difference }\left(\mathrm{e}^{3}\right)\end{array}$ & 1.471 and -0.584 & 1.023 and -0.675 & 1.618 and -0.819 \\
\hline
\end{tabular}




\section{Graphical Abstract}

Structural and coordination propensity of anions direct the connectivity and dimensionality of metapyridyl appended tetramercaptotetrathiacalix[4]arene in 1,3-alternate conformation silver coordination ${ }_{5}$ networks.

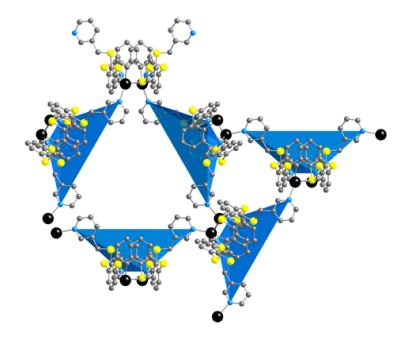

